\section{ORTHOTOPIC CARDIAC TRANSPLANTATION: A COMPARISON OF STANDARD AND BICAVAL WYTHENSHAWE TECHNIQUES}

We describe an alternative technique for orthotopic cardiac transplantation (bicaval Wythenshawe technique), which maintains the right and left atrial anatomy. We compared the new bicaval technique with the conventional (Lower and Shumway) technique of orthotopic cardiac transplantation to identify any beneficial physiologic and clinical outcomes resulting from maintaining the normal anatomy. Seventy-five patients were randomized on an alternate basis to two groups: group $A(n=40)$ had orthotopic cardiac transplantation with the bicaval technique and group B ( $n=35$ ) had conventional orthotopic heart transplantation. All patients were studied with transthoracic echocardiogram, endomyocardial biopsies, and measurement of intracardiac pressures 1, 4, and 12 weeks after transplantation. There were no statistically significant differences in the demographic profile, ischemic time, bypass time, implantation time, transpulmonary gradient, or pulmonary vascular resistance between the two groups. The hemodynamic data were collected in the absence of histologic signs of rejection. In group A right atrial pressure (mean $3.6 \mathrm{~mm} \mathrm{Hg}$ ) was significantly lower $(p<0.03$ ) than in group $B$ (mean $8.8 \mathrm{~mm} \mathrm{Hg}$ ). The right atrial a wave was recorded in 38 patients in group A compared with seven patients in group B $(p=0.041)$. Atrial tachyarrhythmias occurred in two patients in group $A$ compared with 11 in group $B(p<0.016)$. Temporary pacing was required in 10 patients in group $A$ and 16 patients in group $B$ $(p=0.034)$. Four cases of mitral regurgitation (all mild) were detected in group $A$ in comparison with 12 cases ( 10 mild, 2 severe) in group $B(p=0.008)$. The mean ejection fraction in the first week after transplantation was $58 \%$ in group $A$ and $46 \%$ in group $B$ $(p=0.5)$. In the first 3 months the need for diuretics was less in group A (mean dose $80.8 \mathrm{mg}$ furosemide daily) than in group $B$ (mean dose $134 \mathrm{mg}$ furosemide daily in the first week increasing to $160 \mathrm{mg}$ furosemide daily). Hospital stay was shorter in group $\mathrm{A}$ (mean 23 days) than in group B (mean 27 days) $(p<0.015)$. There were no early deaths as a result of right ventricular failure in group $A(n=0 / 40)$ compared with four $(n=$ $4 / 35 ; 9 \%)$ in group B $(p<0.034)$. This difference suggests that bicaval orthotopic cardiac implantation is associated with a lower right atrial pressure, a lower likelihood of atrial tachyarrhythmias, less need for pacing, less mitral incompetence, a lower diuretic dose, and a shorter hospital stay. Early mortality from right ventricular failure is significantly lower in this group, which may be the result of improved right ventricular function owing to effective atrial function. (J THORAC CARDIOvaSC SuRg 1995;109:721-30)

A. El Gamel, MB, ChB, FRCS, N. A. Yonan, MB, ChB, FRCS, S. Grant, MRCP, A. K. Deiraniya, MB, ChB, FRCS, A. N. Rahman, MB, ChB, FRCS, M. A. I. Sarsam, MB, ChB, FRCS, and C. S. Campbell, MB, ChB, FRCS, Manchester, United Kingdom
Loteris ower, ${ }^{1}$ Shumway, ${ }^{2}$ and their associates described the surgical technique for orthotopic cardiac transplantation, in which systemic and pulmonary

From the Wythenshawe Hospital Transplant Unit, Manchester, United Kingdom.

Read at the Twentieth Annual Meeting of The Western Thoracic Surgical Association, Olympic Valley, Calif., June 22-25, 1994.

Address for reprints: Ahmed El Gamel, Wythenshawe Transplant Unit, Wythenshawe Hospital, Southmoor Road, Manchester, M23 9LT, United Kingdom.

Copyright (C) 1995 by Mosby-Year Book, Inc.

$0022-5223 / 95 \$ 3.00+0 \quad 12 / 6 / 62365$ venous communication could be simplified with atrial cuffs, avoiding the technical difficulty of separate caval and pulmonary venous anastomoses. Their technique has been the gold standard for orthotopic cardiac transplantation for the past 25 years. ${ }^{3}$ However, the loss of atrial anatomy, the loss of the atrium's contribution to cardiac function, and the prevalence of tricuspid and mitral valve regurgitation documented on echocardiography, despite normal ventricular function, are causes for concern. $^{4}$

We have described the Wythenshawe bicaval 


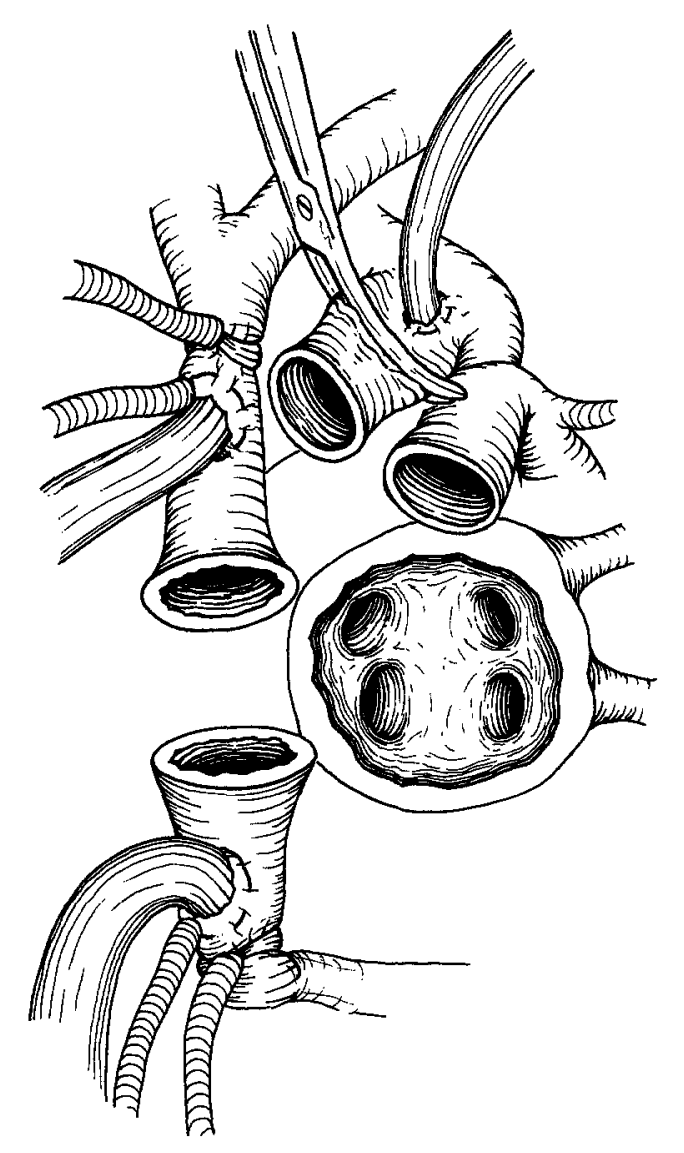

Fig. 1. Wythenshawe bicaval technique. See text for description.

technique, ${ }^{5}$ which has the advantage of maintaining the normal shape of the left atrium and an intact right atrium. The left atrial cuff on the donor heart is anastomosed to the pulmonary venous cuff on the recipient side with a single suture line, which eliminates the difficulties of the recently described total heart transplantation. ${ }^{3}$ The bicaval technique retains the theoretical advantage of normal-shaped atria, which may preserve atrial contractility, sinus node competence, and valvular competence.

We evaluated 40 heart transplant recipients undergoing orthotopic cardiac transplantation by the bicaval technique and 35 patients receiving conventional orthotopic cardiac transplantation to identify any physiologic and clinical differences between these surgical techniques.

\section{Patients and methods}

Patients. Seventy-five consecutive patients (demographic data summarized in Table I) who underwent orthotopic cardiac transplantation at our center between May 1991 and April 1994 were studied after informed
Table I. Demographic profile

\begin{tabular}{lccc}
\hline & $\begin{array}{c}\text { Group } A \\
(n=40)\end{array}$ & $\begin{array}{c}\text { Group B } \\
(n=35)\end{array}$ & p Value \\
\hline Age (yr) & 53 & 50 & 0.14 \\
Weight (kg) & $70.61 \pm 9.6$ & $73.32 \pm 3.3$ & 0.47 \\
Height (cm) & $174 \pm 6.5$ & $173 \pm 8.8$ & 0.77 \\
Sex (M:F) & $31: 9$ & $28: 7$ & 0.46 \\
Pathology & & & \\
$\quad$ IHD & $20(50 \%)$ & $18(51 \%)$ & \\
$\quad$ Cardiomyopathy & $19(47.5 \%)$ & $14(40 \%)$ & \\
$\quad$ Others & $1(2.5 \%)$ & $3(9 \%)$ & \\
TPG (mm Hg) & 7 & 8.5 & 0.24 \\
PVR (WU) & $2.1 \pm 0.8$ & $2 \pm 0.8$ & 0.49 \\
PVRI (WU) & $3.3 \pm 1.3$ & $3.5 \pm 1.1$ & 0.49 \\
\hline
\end{tabular}

$I H D$, Idiopathic heart disease; TPG, transpulmonary gradient; $P V R$, pulmonary vascular resistance; $P V R I$, pulmonary vascular resistance index; $W U$, Wood units.

consent had been obtained. The patients were randomized on an alternate basis to either the Wythenshawe bicaval technique (group A, $n=40$ ) or the standard technique of Lower ${ }^{1}$ and Shumway ${ }^{2}$ (group B, $n=35$ ). Since December 1993 we have changed our randomization protocol to coin tossing.

Surgical technique. Cardiopulmonary bypass was initiated via cannulas placed in the superior (SVC) and inferior (IVC) venal cavae and ascending aorta. The bypass circuit included a DeBakey roller pump (Sarns, Inc., Ann Arbor, Mich.) and a Sorin monolyth membrane oxygenator (Sorin Biomedica S.p.A., Saluggia, Italy). The prime consisted of $1 \mathrm{~L}$ of lactated Ringer's solution and 1 L of Gelofusin solution (B-Braun Medical Ltd., Switzerland). Core temperature is maintained between $26^{\circ}$ and $28^{\circ} \mathrm{C}$.

The Wythenshawe bicaval technique, previously described by Sarsam and colleagues, ${ }^{5}$ consists of excision of the right atrium of the recipient with a 2 to $3 \mathrm{~cm}$ cuff left around each cava (cavoatrial cuff). The left atrial incision is carried to the base of the left atrial appendage, which is removed leaving a small margin of the atrial cuff around all four pulmonary veins (Fig. 1).

The donor heart is excised with an intact right atrium and long cavae. The azygos vein may have to be tied off to provide adequate length on the SVC. The left atrial incision is performed in the usual fashion, to leave an adequate cuff for the pulmonary veins if the lungs are also donated. Donor hearts are arrested with cold St. Thomas' Hospital cardioplegic solution and stored in $4^{\circ} \mathrm{C}$ cold saline solution. Ischemic time is measured from donor aortic crossclamping to release of the recipient aortic crossclamp.

The donor left atrium is sutured to the recipient left atrium with continuous 3-0 Prolene suture (Ethicon, Inc., Somerville, N.J.) in the usual fashion (Fig. 1). Notice that the left atrial shape and size are more or less normal because of the resection of the recipient atrial septum, with only the atrial roof left in situ. By contrast, in the standard technique, the atrial septum as well as a large remnant of the recipient atrial mass is left behind. A left atrial or left ventricular vent is introduced to avoid cardiac 


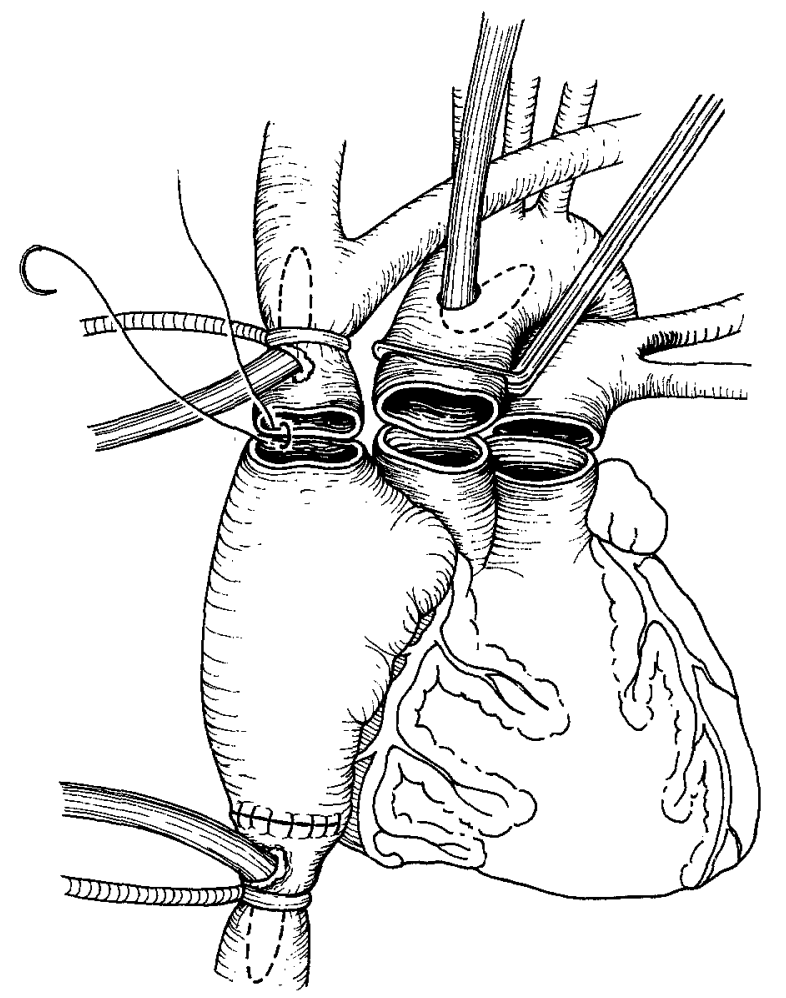

Fig. 2. Wythenshawe bicaval technique. See text for description.

rewarming. The IVC opening is then sutured to the IVC atrial cuff with continuous 4-0 Prolene suture (Fig. 2). The donor SVC is similarly sutured to the recipient SVC-atrial cuff. Care should be taken to avoid any narrowing during suturing that will make future endomyocardial biopsies difficult. Cold blood cardioplegic solution is given after the completion of the atrial suture via the aortic root. The great arteries are then anastomosed with continuous 4-0 Prolene suture in the usual fashion (Fig. 3). Before the release of the crossclamp, a $1 \mathrm{~L}$ shot of aspartate glutamate warm blood cardioplegic solution was given to all patients in both groups. Two atrial pacing wires and two ventricular pacing wires were routinely left in place at the end of each operation.

Immunosuppression. All patients received the standard immunosuppressive drugs (induction therapy; rabbit antithymocyte globulin $2 \mathrm{mg} / \mathrm{kg}$ daily for 3 days, methylpredinsolone $125 \mathrm{mg}$ intravenously for three doses, and maintenance therapy: cyclosporine, steroids, and azathioprine).

Endomyocardial biopsies. Endomyocardial biopsies were performed via the right internal jugular vein in all except $9 \%$ of patients $(n=7 / 75,4$ in group $A, 3$ in group $\mathrm{B}$ ), in whom a femoral vein approach was necessary (6 patients were intolerant to the cervical approach). Intracardiac pressures were measured by introducing a $7 \mathrm{~F}$ multipurpose vascular catheter (Cordis Corp., Miami, Fla.) in all patients at the time of biopsy.

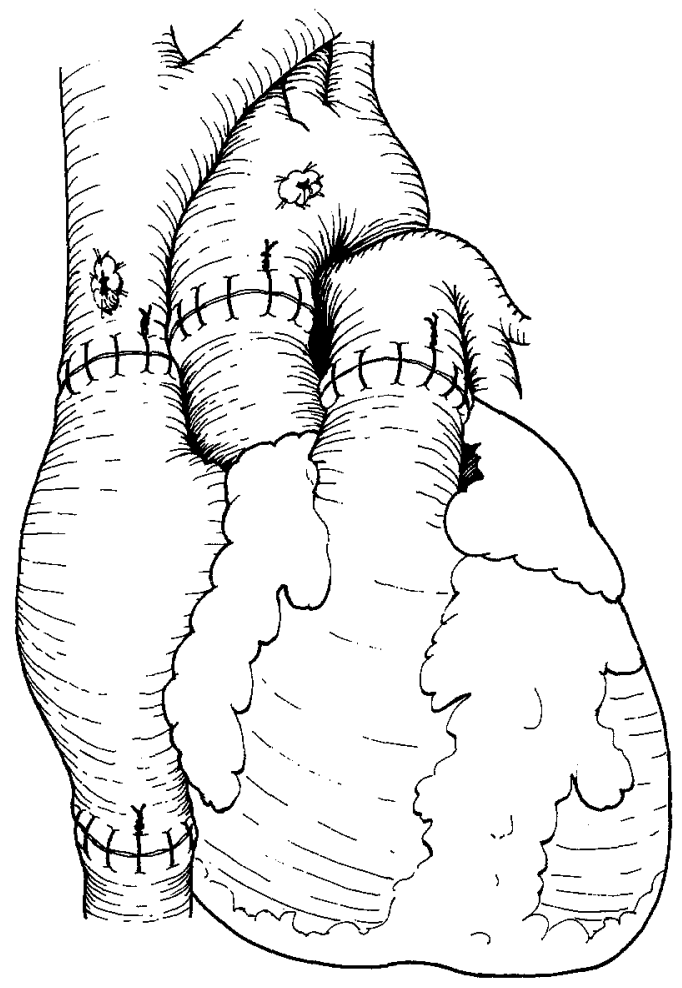

Fig. 3. Wythenshawe bicaval technique. See text for description.

Biopsies were performed weekly on all patients for the first month and every 2 weeks for 2 months. Intracardiac pressures used for comparison were collected when biopsy results showed no histologic signs of rejection. Transthoracic echocardiography was performed routinely after the biopsy in the first 3 months.

Statistics. Data were analyzed with Statview SE+ graphics software (Abacus Concepts, Berkeley, Calif.). All data were expressed as mean values and standard deviation. Data were compared by means of Student's $t$ test and parametric tests: the Mann-Whitney test for continuous variables and the Fisher exact test for categorical variables. Values of $p<0.05$ were accepted as statistically significant.

\section{Results}

Preoperative data. Comparison of the two groups showed no significant differences with regard to preoperative parameters (age, sex ratio, transpulmonary gradient, and pulmonary vascular resistance). Data are summarized in Table $\mathrm{I}$.

Perioperative parameters. Age of the donor, ischemic time, implantation time, and blood loss were not statistically different between the two groups (Table II). 
Table II. Peroperative data and postoperative data

\begin{tabular}{lccc}
\hline & $\begin{array}{c}\text { Group A } \\
(n=40)\end{array}$ & $\begin{array}{c}\text { Group B } \\
(n=35)\end{array}$ & $\begin{array}{c}p \\
\text { Value }\end{array}$ \\
\hline Donor age & $32 \pm 2.3$ & $30.95 \pm 2.3$ & 0.38 \\
Implantation time (min) & 82 & 71 & 0.12 \\
Ischemic time (min) & 197 & 181 & 0.18 \\
Bypass time (min) & 125 & 131 & 0.17 \\
Blood loss in 24 hr (ml) & $764 \pm 453$ & $832 \pm 342$ & 0.56 \\
Atrial tachyarrhythmias & 2 & 11 & 0.016 \\
Temporary pacing & 9 & 17 & 0.034 \\
Permanent pacing & 0 & 3 & 0.1 \\
Hospital stay (days) & 23 & 27 & 0.015 \\
Furosemide dose (mg) & $80.8 \pm 2.9$ & $134 \pm 18.5$ & 0.03 \\
\hline
\end{tabular}

Postoperative data. Patients were extubated 8 to 48 hours after their arrival in the intensive care unit. Four patients intubated for 4 to 21 days died of right ventricular failure in group B. One patient in group A was intubated for 7 days and survived early right ventricular failure, which necessitated mechanical support.

Arrhythmias and pacing. Atrial tachyarrhythmias occurred in two patients in group A compared with 11 patients in group B $(p<0.016)$. Temporary pacing was required in 10 patients in group $A$ and 17 patients in group B $(p=0.034)$. Permanent pacing was needed in three patients in group $\mathrm{B}$, whereas none of the patients subjected to the bicaval technique required permanent pacing $(p=0.09)$ (see Table II).

Echocardiography. Two-dimensional transthoracic echocardiography showed normal-shaped right and left atria in group A (Fig. 4), compared with the hourglass-shaped left atrium described in the conventional technique. ${ }^{5}$ Doppler study showed tricuspid valve regurgitation in 15 patients from group $\mathrm{A}$ versus 17 from group $B$ in the first week after transplantation. The incidence and severity were slightly higher in group B and this trend persisted 3 months after transplantation (Fig. 5). Mild mitral regurgitation was detected in four patients in group A versus 12 patients (10 mild and 2 severe) in group B. The trend persisted at 3 months, as shown in Fig. $6(p<0.05)$. The mean ejection fraction in the first week after transplantation was $58 \%$ in group $\mathrm{A}$ and $46 \%$ in group B. This difference was not statistically significant and the trend disappeared at 3 months.

Atrial contraction. Recording of pulsed Doppler velocimetry at the level of the tricuspid and mitral valves showed a normal atrial systolic wave in group A compared with an erratic or absent atrial systolic wave in group B. Recorded right atrial traces showed the presence of a right atrial a wave in 95\% $(n=38 / 40)$ of patients in group A. An a wave was recorded in $20 \%(n=7 / 35)$ of patients in group $\mathrm{B}$, $p=0.041$ (Table III).

Hemodynamic parameters. The hemodynamic parameters were measured at 1,4 , and 12 weeks (Table III). Right atrial pressure in group A (mean $3.6 \mathrm{~mm} \mathrm{Hg}$ ) was significantly lower $(p<0.03$, Student's $t$ test) than in group B (mean $8.8 \mathrm{~mm} \mathrm{Hg}$ ). Mean pulmonary artery pressure was slightly higher in group B (22.9 $\mathrm{mm} \mathrm{Hg}$ versus $17.4 \mathrm{~mm} \mathrm{Hg}$ in group A). Right ventricular and pulmonary capillary wedge pressures and mixed venous oxygen saturations were not statistically different between the two groups. This trend persisted in the first 3 months after transplantation (Table III).

Diuretic therapy, hospital stay, and early mortality. In the first 3 months the need for diuretics was less in group A (mean dose $80.8 \mathrm{mg}$ furosemide daily) than in group B (mean dose $134 \mathrm{mg}$ furosemide daily in the first week increasing to $160 \mathrm{mg}$ furosemide daily) and remained unchanged. The hospital stay was shorter in group A (mean 23 days) than in group $\mathrm{B}$ (mean 28 days) $(p<0.015)$. The early mortality resulting from right ventricular failure was $0 \%(n=0 / 40)$ in group $\mathrm{A}$ and $9 \%(n=$ $4 / 35)$ in group B $(p<0.034)$. Patients who died of right ventricular failure had comparable donor age, ischemic time, transpulmonary gradient, pulmonary vascular resistance, and pulmonary vascular resistance index to the survivors in the bicaval group (Table IV).

\section{Discussion}

Lower, ${ }^{1}$ Shumway, ${ }^{2}$ and their associates recognized early that systemic and pulmonary venous connections could be simplified with atrial cuffs, avoiding the technical difficulty of separate caval and pulmonary venous anastomoses. Their technique is simple to perform and has yielded good early and long-term results. However, some concern exists about atrial anatomy and function. Atrial contraction boosts pump function and contributes $15 \%$ to $20 \%$ of the net stroke volume. After standard orthotopic heart transplantation the a wave representing ventricular filling by the atrium is smaller or not apparent. ${ }^{6}$

Several studies have shown that tricuspid and mitral valve regurgitation is prevalent on echocardiography after conventional transplantation, despite a normal valve apparatus. ${ }^{4,7}$ Mild to moderate tricuspid regurgitation was present in $67 \%$ of pa- 


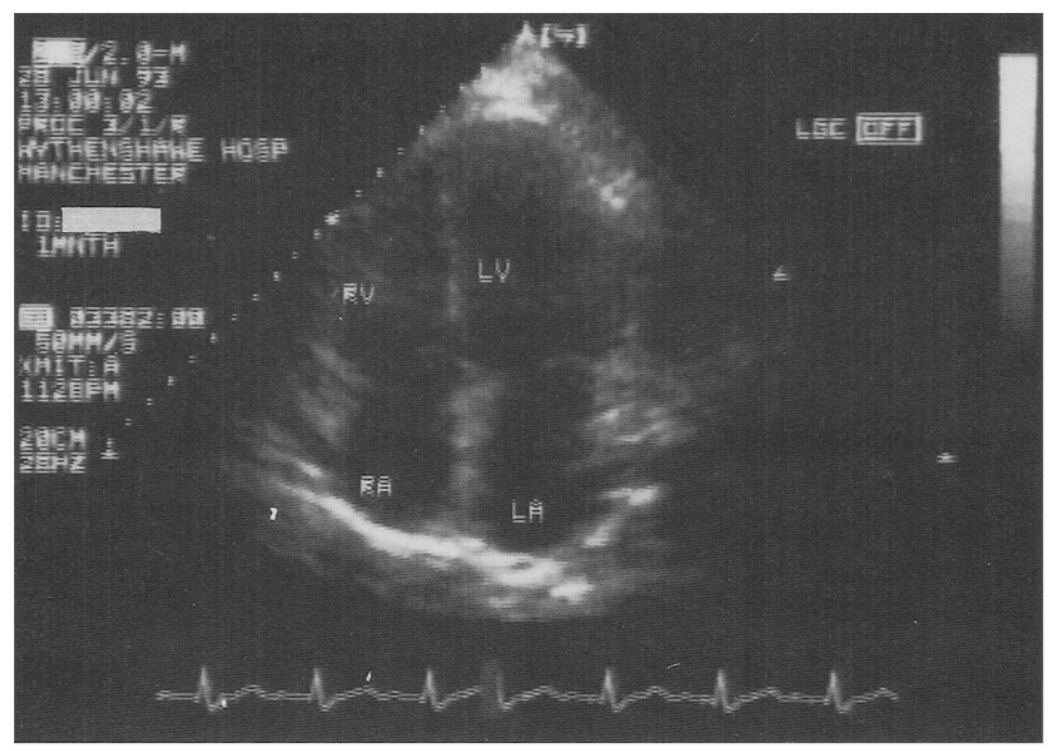

Fig. 4. Echocardiographic appearance of four-chamber view in a patient from the bicaval group. Note the normal-sized atria. $R V$, Right ventricle; $L V$, left ventricle; $R A$, right atrium; $L A$, left atrium.

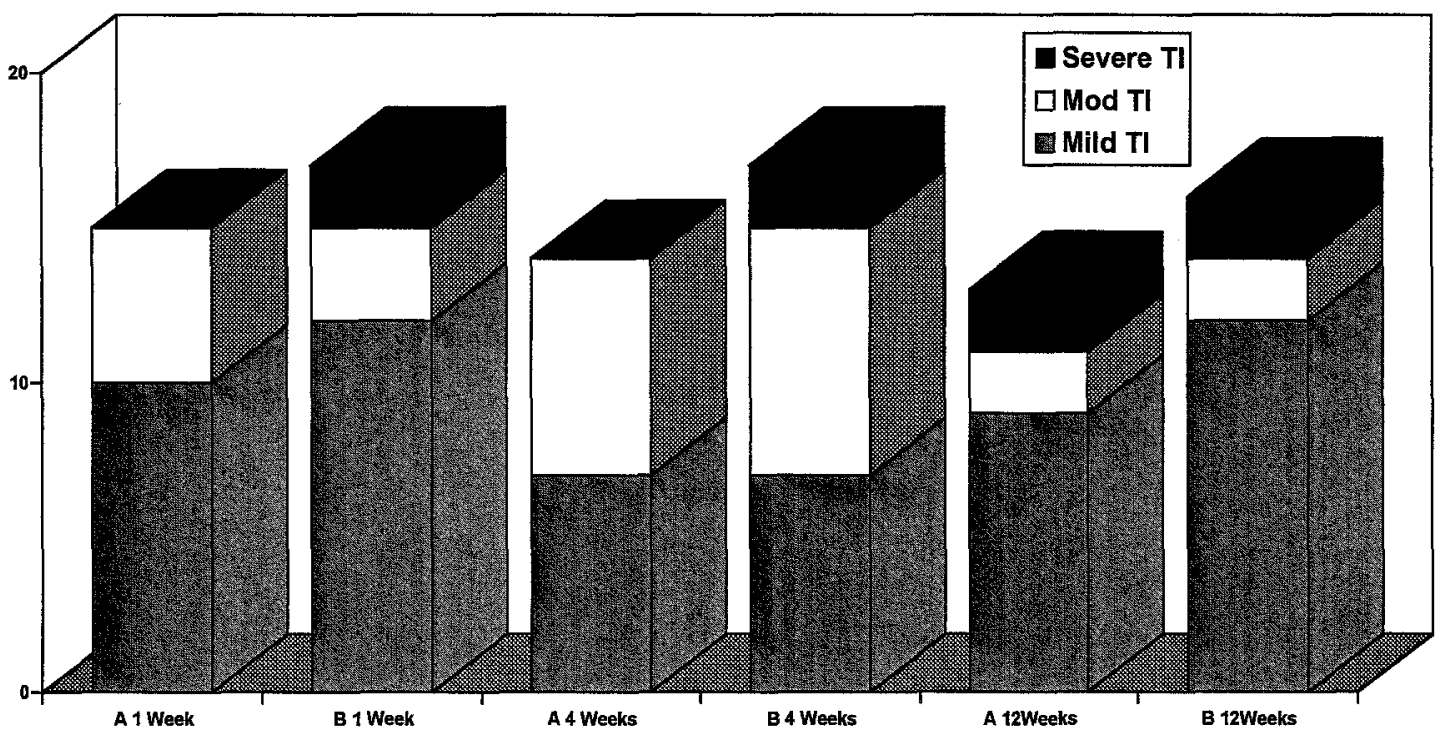

Fig. 5. Echocardiographic assessment of tricuspid valve in group A and group b at 1 week, 4 weeks, and 12 weeks after transplantation. The number of patients with mild, moderate, or severe tricuspid incompetence $(T I)$ did not differ significantly among the groups ( $p=$ not significant).

tients in the first 24 hours. ${ }^{8}$ This regurgitation may be due to the creation of abnormal-shaped atria and the asynchronous contraction of the recipient and the donor atria. Studies have also shown that the atria are enlarged and abnormal in shape..$^{9-11}$

The only predictable disturbance of the mitral apparatus components described was the "snowman" enlargement of the left atrium. ${ }^{11}$ The poste- rior mitral leaflet, which is continuous with the left atrial endocardium, may be critically distorted by atrial dilatation. Although the role of the normal left atrium in mitral competence may also include synchronous contraction, the contribution of atrial contraction to mitral competence with normal ventricular function has been considered minimal. ${ }^{11}$ In addition, no beat-to-beat variation in mitral regur- 


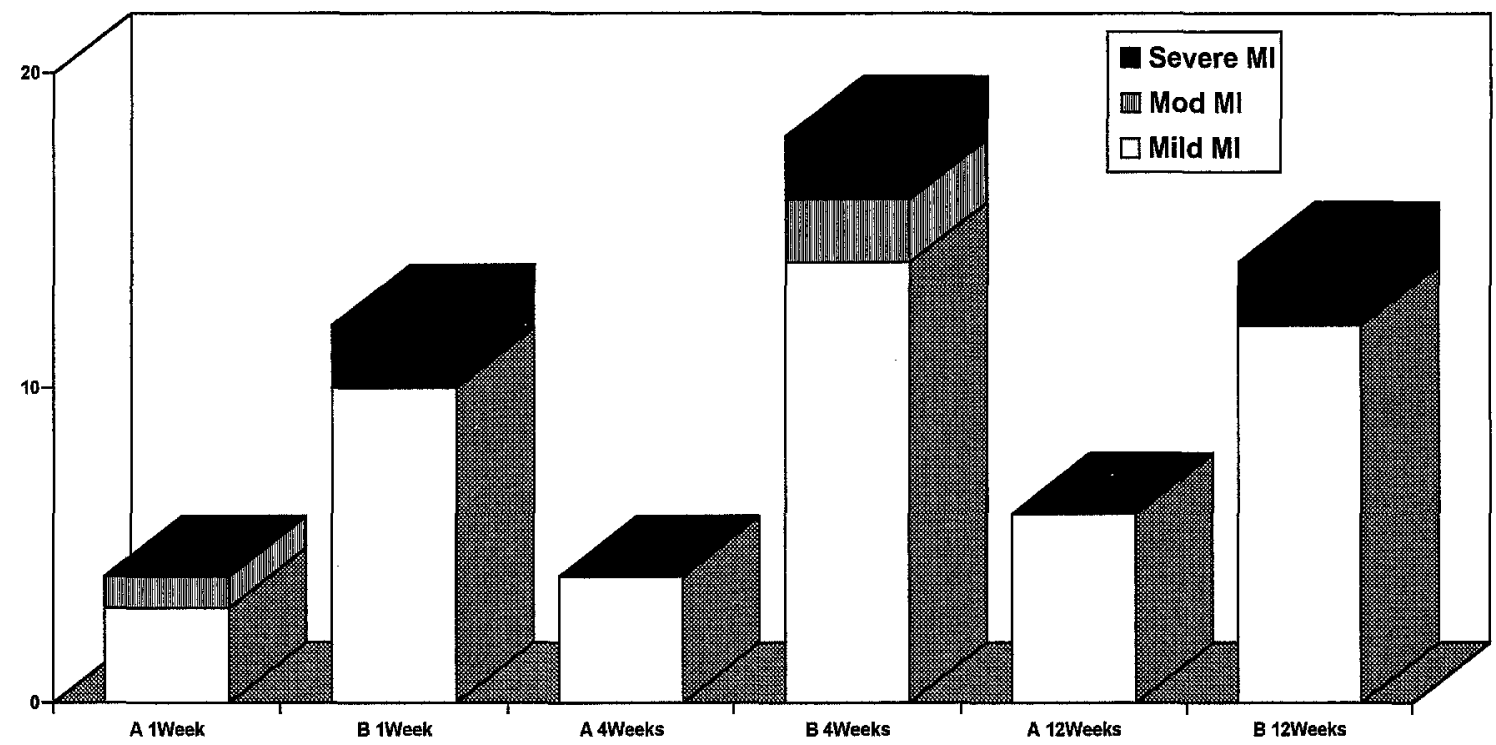

Fig. 6. Echocardiographic assessment of mitral valve in group A and group B at 1 week, 4 weeks, and 12 weeks after transplantation. The number of patients with mild, moderate, or severe mitral incompetence $(M I)$ in each group was not significantly different $(p<0.05)$.

Table III. Posttransplantation hemodynamics

\begin{tabular}{lccc}
\hline & Group A & Group B & $p$ Value \\
\hline A wave detected & 38 & 7 & 0.041 \\
Right atrial pressure & $3.6 \pm 2.7$ & $8.8 \pm 7.0$ & 0.03 \\
Peak A pressure & $5.6 \pm 3$ & $9.2 \pm 0.5$ & \\
Right ventricular pressure & $28.6 \pm 4.7$ & $30 \pm 8$ & 0.36 \\
Pulmonary artery pressure & $17.4 \pm 4.2$ & $22.9 \pm 10.6$ & 0.04 \\
Wedge pressure & $9.1 \pm 4.3$ & $10 \pm 3.1$ & 0.19 \\
Mixed venous oxygen & $69.7 \pm 3.4$ & $66.5 \pm 8.2$ & 0.18 \\
$\quad$ & & & \\
\hline
\end{tabular}

gitation was detectable, which would be expected if discordant atrial contraction were responsible.

Anatomic abnormalities are also associated with physiologic abnormalities, mainly the asynchronous contractions of the recipient and the donor atria ${ }^{9}$ with phasic excursion of the atrial septum during the cardiac cycle. These abnormalities could lead to atrioventricular insufficiency, which is being frequently seen after orthotopic heart transplantation. $7,9,12$

The influence of recipient atrial contraction on ventricular filling has been studied and may be crucial in the early postoperative phase. ${ }^{13}$ In an animal model of right-sided electrical isolation, Goldstein and associates ${ }^{14}$ showed that the increase of right atrial contractility constitutes an important compensatory response to right ventricular dysfunction as shown by the deleterious hemodynamic effects of atrioventricular dyssynchrony. In addition,
Table IV. Dead compared with survivors

\begin{tabular}{lccc}
\hline & $\begin{array}{c}\text { Died }<30 \\
\text { days of } R V \\
\text { failure }\end{array}$ & $\begin{array}{c}\text { Survived } \\
>30 \text { days }\end{array}$ & $\begin{array}{c}p \\
\text { Value }\end{array}$ \\
\hline$n$ & 4 & 40 & \\
age & 53 & 53 & 0.09 \\
Donor age & $36 \pm 5.2$ & $32 \pm 2.3$ & 0.2 \\
Ischemic time & 210 & 197 & 0.09 \\
Implantation time & $72 \pm 15$ & $82 \pm 18$ & 0.61 \\
Bypass time & $142 \pm 14$ & $125 \pm 18$ & 0.42 \\
Transpulmonary gradient & $8 \pm 1.2$ & $8 \pm 1.5$ & 0.18 \\
PVR & $2.3 \pm 0.8$ & $2.1 \pm 0.8$ & 0.47 \\
PVRI & $4.5 \pm 1.6$ & $3.3 \pm 1.3$ & 0.40 \\
\hline
\end{tabular}

PVR, Pulmonary vascular resistance; $P V R I$, pulmonary vascular resistance index.

atrioventricular dyssynchrony results in tricuspid regurgitation, which further compromises right ventricular performance. Goldstein and associates ${ }^{15}$ confirmed these findings in patients with right ventricular infarction and showed that patients with atrioventricular dyssynchrony or depressed a waves (an indication of right atrial function) are severely compromised. After the Fontan operation in patients with tricuspid atresia or with single ventricle, the role of right atrial contraction becomes more important in patients with small pulmonary arteries. ${ }^{16}$

What is important, however, is the role of an intact right atrium in preventing the development of right ventricular failure after orthotopic heart trans- 
plantation, particularly in patients with marginally elevated pulmonary vascular resistance.

The incidence of tachyarrhythmias appears to be between $18 \%$ and $44 \%{ }^{17}$; the rate of early bradycardias is $38 \%$ and of support pacing, $40 \%{ }^{18}$ Several studies have also documented a $5 \%$ to $20 \%$ incidence of permanent pacing after conventional transplantation. ${ }^{17,19}$ Sinus dysfunction is frequently seen after orthotopic heart transplantation ${ }^{20,21}$ and may contribute to the hemodynamic abnormalities observed after orthotopic heart transplantation. ${ }^{22}$

The technique of total cardiac transplantation ${ }^{23}$ was recently introduced by Yacoub, ${ }^{3}$ Dreyfus, ${ }^{24}$ and their associates to minimize the aforementioned disadvantages of the standard technique. Separate anastomoses were done for the right and left pulmonary veins, the SVC, and the IVC. Total cardiac transplantation is technically more demanding and requires a longer implantation time than the conventional technique, and the posterior suture line of the pulmonary venous anastomosis is inaccessible. Hemodynamic evaluation after total heart transplantation (right atrial, right ventricular, pulmonary arterial, and pulmonary capillary wedge pressures and cardiac output) did not demonstrate a significant difference compared with the standard technique. ${ }^{25}$ The number of patients included in the study was small, and the measurement of cardiac output very early after transplantation (first week) was influenced by many factors to make the comparison reliable in a small group of patients. ${ }^{25}$

Kendall and coworkers ${ }^{26}$ showed no difference between patients with total cardiac transplantation or with the "standard" technique in the prevalence of tricuspid regurgitation or hemodynamic abnormalities. Their observations are contrary to those of the present study, in which hemodynamic benefit of preservation of atrial anatomy and function was observed in the improvement of the clinical outcome of the bicaval group.

The data available in the present study were insufficient to describe more precisely the right ventricular function. Different methods are available to assess right atrial and right ventricular function. Right atrial pressure does not accurately predict the right ventricular preload. ${ }^{27}$ However, the analysis of right atrial waveforms, including measurement of a wave and $\mathrm{V}$ wave amplitude, provides interesting data on right atrial function. ${ }^{14}$

The degree of tricuspid regurgitation was evaluated semiquantitatively in the present study by the Doppler mapping technique. The absence of a $\mathrm{V}$ wave on the right atrial pressure curve ${ }^{28}$ and the absence of a systolic murmur ${ }^{7}$ suggested that tricuspid regurgitation was absent or only mild to moderate.

Tricuspid valve incompetence affected $37.5 \%$ of patients in group A and $48.5 \%$ of patients in group B the first week. The prevalence is similar when the standard group (67\% in the first 24 hours) ${ }^{8}$ is compared with the total heart transplantation group, although the severity is less in the bicaval group. Echocardiographic studies showed that the right ventricle is dilated at day 1 after transplantation and remains dilated at 1 month., ${ }^{89}$ Right ventricular failure in the transplanted heart results classically from excessive right ventricular afterload. ${ }^{30,31}$ The role of ischemic time of the transplanted heart ${ }^{32}$ and the age of the donor ${ }^{33}$ have also been discussed. ${ }^{22,34}$ We have found no differences in ischemic time and donor age between the two groups to account for our findings. Right ventricular dysfunction and tricuspid valve incompetance are common regardless of the transplantation technique. However, the advantage of the bicaval technique may be the spur provided by the intact atrium and sinus rhythm, which maintain adequate cardiac output. Right ventricular failure occurred in one patient in the bicaval group who had a high pulmonary vascular resistance. The patient required mechanical support but completely recovered, which may indicate that in this subgroup of patients the preservation of atrial function may aid recovery in the early postoperative phase.

Our annual mortality from right ventricular failure is $4 \%$ (reporting all cases done by both techniques). We were surprised to find that most of the deaths occurred in the standard group, to increase the incidence $9 \%$ when only the standard group was analyzed.

Further hemodynamic studies are required to confirm the advantages of this technique, especially in cases in which pulmonary vascular resistance is elevated. The role of atrial size and geometry in the right ventricular dysfunction observed after orthotopic heart transplantation using the standard technique remains to be evaluated.

Our technique as described is simple to perform. All suture lines are easily accessible. Neither SVC nor IVC obstruction has occurred. The present study demonstrated better preservation of the atrial anatomy, contractility (preserved a wave), and sinus node activity, which may contribute to better right ventricular and left ventricular function. ${ }^{20} \mathrm{We}$ have 
shown that the bicaval technique has a lower incidence of mitral incompetence, which may be due to the absence of the anticlockwise rotation incurred with conventional cardiac transplantation and the synchronized atrial contraction. We have also shown clinical advantages of the bicaval techniques: shorter hospital stay, lower diuretic dose, and lower early mortality. In this study, the four deaths in the standard group resulted from right ventricular failure; this problem did not develop in any patients who had the new technique. No difference in donor age, ischemic time, transpulmonary gradient, pulmonary vascular resistance, and pulmonary vascular resistance index was observed between patients who died of right ventricular failure and patients who survived (Table IV).

Preservation of normal sinus rhythm and reduced need for temporary as well as permanent pacemakers in group A may prevent or reduce the impact of right ventricular failure after transplantation.

Independently, Blanche and associates ${ }^{35}$ reported their experience with a similar technique for performing cavocaval anastomosis, which may have the disadvantage of suture line tension in cases with a major size discrepancy between donor and recipient, increasing the risk of caval narrowing. We were interested to note that their results are comparable with ours, confirming the advantages of preserving atrial anatomy and function. Currently the bicaval technique is our preferred technique for orthotopic cardiac transplantation.

\section{REFERENCES}

1. Lower RR, Stofer RC, Shumway NE. Homovital transplantation of the heart. J THORAC CARDIOVASC SURG 1961;41:196.

2. Shumway NE, Lower R, Stofer RC. Transplantation of the heart. Adv Surg 1966;2:265-84.

3. Yacoub M, Mankad P, Ledingham S. Donor procurement and surgical techniques for cardiac transplantation. Semin Thorac Cardiovasc Surg 1990;2:153-61.

4. Angermann CE, Spes CH, Tammen AR, et al. Transesophageal echocardiography after orthotopic heart transplantation. Int J Card Imaging 1990;5:271-4.

5. Sarsam MA, Campbell CS, Yonan NA, Deiraniya AK, Rahman AN. An alternative surgical technique in orthotopic cardiac transplantation. J Card Surg 1993;8:344-9.

6. Hosenpud JD. Physiology and hemodynamic assessment of the transplanted heart. In: Hosenpud JD, Cobanoglu A, Normal DJ, ed. Cardiac transplantation. 1st ed. New York: Springer-Verlag, 1991:169-71.

7. Lewen MK, Bryg RJ, Miller LW, Williams GA,
Labovitz AJ. Tricuspid regurgitation by Doppler echocardiography after orthotopic cardiac transplantation. Am J Cardiol 1987;59:1371-4.

8. Bhatia SJS, Kirshenbaum JM, Shemin RJ, et al. Time course of resolution of pulmonary hypertension and right ventricular remodeling after orthotopic cardiac transplantation. Circulation 1987;4:819-26.

9. Angermann CE, Spes CH, Tammem A, et al. Anatomic characteristics and valvular function of the transplanted heart: transthoracic versus transesophageal echocardiographic findings. J Heart Transplant 1990;9:331-8.

10. Bommer W, Weinert L, Neumann A, Neef J, Mason DT, DeMaria A. Determination of right atrial and right ventricular size by two-dimensional echocardiography. Circulation 1979;60:91-100.

11. Stevenson LW, Dandourian BJ, Kobashigawa J, et al. Mitral regurgitation after cardiac transplantation. Am J Cardiol 1987;60:119-22.

12. Mugge A, Daniel WG, Hermann G, Simon R, Lichtlen PR. Quantification of tricuspid regurgitation by Doppler color mapping after cardiac transplantation. Am J Cardiol 1990;66:884-7.

13. Valantine HA, Appleton CP, Hatle LK, et al. Influence of recipient atrial contraction on left ventricular filling: dynamics of the transplanted heart assessed by Doppler echocardiography. Am J Cardiol 1987;59: 1159-63.

14. Goldstein JA, Harada A, Yagi Y, Barzilai B, Cox JL. Hemodynamic importance of systolic ventricular interaction, augmented right atrial contractility and atrioventricular synchrony in acute right ventricular dysfunction. J Am Coll Cardiol 1990;16: 181-9.

15. Goldstein JA, Barzalai B, Rosamond TL, et al. Determinants of hemodynamic compromise with severe right ventricular infarction. Circulation 1990;82:35968.

16. Nakazawa $M$, Nojima $K$, Okuda $H$, et al. Flow dynamics in the main artery after the Fontan procedure in patients with tricuspid atresia or single ventricle. Circulation 1987;75:1117-23.

17. Jacquet L, Ziady G, Stein K, et al. Cardiac rhythm disturbances early after orthotopic heart transplantation: prevalence and clinical importance of the observed abnormalities. J Am Coll Cardiol 1990;16: 832-7.

18. Romhilt DW, Doyle M, Sagar KB, Hastillo A, et al. Prevalence and significe of arrhythmias in long-term survivors of cardiac transplantation. Circulation 1982; 66:219-22.

19. Heinz G, Hirsch1 M, Buxbaum P, Laufer G, Gasic S, Laczkovics A. Sinus node dysfunction after orthotopic cardiac transplantation: postoperative incidence and long term implications. PACE 1992;15:731-6.

20. Midei MG, Baughman KL, Achuff SC, Walford GD, 
Baumgarten W, Brinker JA. Is atrial activation beneficial in heart transplant recipient? J Am Coll Cardiol 1990;16:1201-4.

21. Heinz G, Ohner T, Laufer G, Gossinger H, Gasic S, Laczkovics A. Demographic and periperative factors associated with initial and prolonged sinus node dysfunction after orthotopic heart transplantation. the impact of ischemic time. Transplantation 1991;51: 1217-32.

22. Trento A, Hardesty RL, Griffith BP, Kormos RL, Bahnson HT. Early function of cardiac homografts: relationship to hemodynamics in the donor and length of the ischemic period. Circulation 1986;74(Suppl):III7.

23. Couetil JP, Mihaileanu S, Lavergne T, et al. Total excision of the recipient atria (TERA) in orthotopic heart transplantation (OHT) as a new clinical procedure: technical consideration and early results. J Heart Lung Transplant 1991;10:101.

24. Dreyfus G, Jebara V, Mihailueanue S, Carpentier AF. Total orthotopic heart transplantation: an alternative to the standard technique. Ann Thorac Surg 1991;52: 1181-4.

25. Bizouarn TM, Portier D, Train M, Michaud JL. Right ventricular function early after total or standard orthotopic heart transplantation. Ann Thorac Surg 1994;57:183-7.

26. Kendall SWH, Ciulli F, Mullins PA, et al. Total orthotopic heart transplantation: an alternative to the standard technique. Ann Thorac Surg 1992;54:187-8.

27. Martyn JAJ, Snider MT, Farago LF, Burke JF. Thermodilution right ventricular volume: a novel and better predictor of volume replacement in acute thermal injury. J Trauma 1981;21:619.

28. Young JB, Leon CA, Short HD, et al. Evolution of hemodynamics after orthotopic heart and heart lung transplantation: early restrictive patterns persisting in occult fashion. J Heart Transplant 1987;6:34-43.

29. Fasoli G, Scognamiglio R. Studio ecografico nel trapiantocardiaco. G Ital Cardiol 1989;19:115-60.

30. Pascual JMS, Fiorelli A, Bellotti GM, Stolf NAG, Jatene AD. Protacyclin in the management of pulmonary hypertension after heart transplantation. J Heart Transplant 1990;9:51-64.

31. Clark NJ, Martin DR. Anesthetic considerations for patients undergoing cardiac transplantation. J Cardiothorac Anaesth 1988;2:519-42.

32. Kawaguchi A, Gandjbakch I, Pavie A, et al. Cardiac transplant recipients with preoperative pulmonary hypertension: evolution of pulmonary hemodynamics and surgical options. Circulation 1989;80(Suppl): III90-6.

33. Wahlers T, Beer C, Fieguth HG. Right heart failure following orthotopic cardiac. Clin Transplant 1988;2: 252-6.

34. Pflugfelder PW, Thomson D, Singh NR, Menkis AH, Mckenzie FN, Kostuk WJ. Cardiac allograft ischemic time: relation to graft survival and cardiac function. Circulation 1989;80(Suppl):III116-21.

35. Blanche C, Czer LSC, Valenza M, Trento A. Alternative technique for orthotopic heart transplantation. Ann Thorac Surg 1994;57:756-67.

\section{Discussion}

Dr. Bruce A. Reitz (Stanford, Calif.). The Lower-Shumway technique was originally introduced in 1959 to simplify cardiac transplantation, with others having suggested caval anastomosis. With modern suture techniques, it is now easy to perform these caval anastomoses and even pulmonary venous anastomoses. The technique that you described provides an aesthetically pleasing appearance to the heart once it has been implanted. However, I want to ask you three questions about your data to better understand the differences that you have mentioned.

The first question addresses randomization of patients into the study. The abstract suggests that patients are randomized and yet the manuscript says they were assigned. Are these sequential patients with the ShumwayLower technique used in the first 40 and then the bicaval technique in the last 35 ?

Dr. El Gamel. In the first stage randomization was done on an alternate basis up to 20 cases, one case bicaval and one case standard. After that we started to think we should randomize them properly. With the difficulty of matching the donor and recipient and the timing of transplantation, we decided that the best way to randomize them was tossing a coin. That is what we are doing at the moment. Standard and bicaval techniques are chosen by tossing a coin.

Dr. Reitz. In the manuscript you added five additional patients and all of those were in the bicaval group, so I wondered if you were still randomizing at that point.

Dr. El Gamel. Yes, we were, by the toss of a coin. That is why the number is quite unequal.

Dr. Reitz. Because of this question of randomization, some things like length of stay and diuretics may be somewhat suspect in the analysis.

I have a question about the four deaths that are reported with the Shumway-Lower technique. If I understand the numbers correctly, that is about an $11.5 \%$ incidence. Most people who have used this technique would say the incidence of right heart failure and death is probably closer to $2 \%$ or $3 \%$. Could you explain the fairly high incidence of this complication?

Dr. El Gamel. We compared these data with our total database of 200 transplant patients, and we found that in this particular series mortality is higher than our average, which is $6 \%$. We have no explanation for that.

Dr. Reitz. I noticed that you used mechanical support in the one patient with bicaval anastomosis who had this problem but did not mention whether you had used mechanical support in the other patients.

Dr. El Gamel. We have used mechanical support in the other patients. The reason is that the patients had rightsided heart failure for 10 days. They were supported by inotropic and mechanical support and the condition of most of them deteriorated in rapid fashion.

Dr. Reitz. Like you, I was surprised by the fact that the 
prevalence of tricuspid insufficiency is quite similar between the two techniques. This is the area in which one would expect the greatest difference between the two. On the other hand, the incidence of mitral regurgitation was apparently significantly different. Because the techniques are basically the same for the left atrium, I have a hard time understanding that discrepancy. I wonder if you could postulate why that might be the case.

Dr. El Gamel. The reason for valve insufficiency has been a controversial issue in cardiac transplantation. There is even a series describing the early mitral incompetent state from the standard technique with no great explanation of why it happens with normal left ventricular function. The only explanation we have was the large atria with the standard technique. The small normal atrial size, as well as the normal geometric position of the left ventricle, may assist the closure of the mitral valve and probably reduce the incidence of incompetence. However, until now that also was surprising to us and we have to find the answer to that.

Dr. Reitz. It does not seem to make sense, but many things in medicine do not. We at Stanford are increasingly using this technique, especially for patients with congenital heart disease and those with a big discrepancy between the right atrium of the recipient and the donor, not only for heart transplantation but also for heart-lung transplantation. It certainly does produce an aesthetically more pleasing appearance of the heart after the operation.

Dr. Alfredo Trento (Malibu, Calif.). We have been using the total orthotopic technique for the past 3 years. We have used your technique when retrieval of both lungs was demanding the posterior atrial wall. You have a prospective series and we have a retrospective series of two consecutive groups. We reviewed about 70 patients in each group. The standard technique was used before 1991 and the new technique after that date. We reached the same conclusion that you reached in your prospective study, with some differences. Hospital survival was $100 \%$ with the new technique, whereas one patient treated by the old technique died of right heart failure. I noticed that four of your patients died of right heart failure. On the basis of their hemodynamics, they did not have right heart failure. I am questioning the cause of death as diagnosed.

Regarding hemodynamics, we have used Doppler echocardiography and cine magnetic resonance imaging during follow-up of patients treated by the new technique. We noticed that the right atrial ejection fraction was much better with the new technique than with the old technique. It was similar to that of a group persons with normal heart function, but the cardiac output was exactly the same, at rest. Our conclusion at this point is that the new technique is more aesthetically pleasing, completely eliminates the need for a pacemaker, and possibly will increase cardiac function during exercise. Can you comment on this please?

Dr. El Gamel. We have actually started exercise studies in both groups to demonstrate if there is any difference in their exercise capacity. That information is being compiled.

Regarding cardiac output measurements, we have started to do something that is more controlled than an absolute comparison of the two groups in cardiac output measurements with numbers. We are using the patient as his or her own control. In the standard technique in the early postoperative period, we got two atrial pacing wires and two ventricular pacing wires. We measure the cardiac output in a resting state, then pace the heart atrially in the resting state, and then pace the heart ventricularly in the resting state. We compare the cardiac function with atrial and ventricular pacing to see if any difference between the two groups is demonstrable. So far, we have been pleased that there is a difference in cardiac output between atrial and ventricular pacing in the bicaval group with an intact atrium. We probably will present this information soon.

Dr. Davis Drinkwater (Los Angeles, Calif.). We started using this technique several years ago and have compiled about 125 cases. It is aesthetically pleasing, and it is good for patients with congenital heart disease. However, we evaluated tricuspid and mitral valve regurgitation and did not see any difference between the two groups, that is, the standard right atrial versus the bicaval connection. We were very surprised. We have not done any exercise studies, but we are hoping that over the long term there may be some benefits similar to the experience with Senning patients, in terms of prevention of future atrial arrhythmias and overall preservation of good ventricular function. Although we do not have any specific measureable differences, we do continue to use the bicaval implantation technique, in large part because of the aesthetic advantages. Is the difference in mitral regurgitation found in your study related more to the time period in which it was done, reflecting better preservation techniques and postoperative management, rather than the bicaval connection itself?

Dr. EI Gamel. Our mitral incompetence data actually were a surprise to us. We did not expect to see a difference. Further investigations are required to demonstrate the reasons. 